\title{
A internacionalização da Biblioteca Nacional: identificação das ações nos relatórios institucionais (1905-1915)
}

\author{
Carlos Henrique Juvêncio
}

\begin{abstract}
Bibliotecário, Mestrando do Programa de PósGraduação da Universidade de Brasília
\end{abstract}

Georgete Medleg Rodrigues

\begin{abstract}
Professora doutora do Programa da PósGraduação em Ciência da Informação da Universidade de Brasília
\end{abstract}

No início do século $X X$, no bojo das ações de modernização do próprio Estado, a Biblioteca Nacional brasileira manteve um profícuo intercâmbio com várias instituições internacionais. Por meio das informações contidas em seus relatórios institucionais, buscou-se, neste artigo, evidenciar as ações empreendidas pela Biblioteca Nacional na busca do que denominamos sua "internacionalização", no período de 1905 a 1915. Para tanto, utilizamos, como procedimento metodológico, o levantamento das seções dos relatórios, selecionando aquelas cujos títulos referiam-se a essas ações de internacionalização. Em seguida, procedemos à análise de cada seção, extraindo as informações que corroboravam com os objetivos da pesquisa. A título de conclusão ainda parcial, constatou-se que a Biblioteca Nacional buscou, de fato, contatos com instituições estrangeiras, visando à modernização de seus métodos e técnicas de tratamento de seu acervo, bem como a recuperação de parte da história do Brasil nos arquivos do exterior, além de realizar ações de intercâmbio com diversas instituições.
Palavras-chave:
Biblioteca
Nacional; Internacionalização; Relatórios institucionais; Memória institucional. 


\section{The internationalization of the national library: identification of actions in the institutional reports (1905-1915)}

In the early twentieth century, in the midst of modernization actions of the state itself, the Brazilian National Library held a fruitful exchange with various international institutions. Through the information contained in its reports institutional sought, in this article, to show the actions undertaken by the National Library in search of what we call its "internationalization" in the period from 1905 to 1915. We used as a methodological procedure, the removal of sections of the reports, selecting those whose titles were related to these actions internationalization. Then we analyzed each section, extracting the information that corroborated with the research objectives. In conclusion even partial, it was found that the National Library of fact sought contacts with foreign institutions, aimed at modernizing their methods and techniques of treating its collection as well as the recovery of part of Brazil's history in the archives of exterior, and perform actions exchanges with various institutions.

Keywords: Institutional memory; Institutional reports; Internationalization; National Library.

Recebido em 15.04.2013 Aceito em 30.04.2013

\section{Introdução}

Os relatórios institucionais são importantes fontes de informação sobre a história das instituições. Em geral, eles servem de prestação de contas sobre um determinado período de tempo, arrolando dados quantiqualitativos sobre as ações e os planos institucionais, descrevendo metas e propostas. Esses documentos fazem parte daquilo que em Arquivologia denominamos Fundo, no caso em exame, Fundo Biblioteca Nacional, isto é, os arquivos produzidos pela própria instituição. Assim, eles são, na expressão de Duranti (1994), registros de ações, que podem ou não ter efeito legal, mas que testemunham sua existência. Nesse sentido, podemos afirmar que os relatórios institucionais são parte integrante da memória institucional, pois, neles, podemos encontrar indícios das suas ações/planos mais relevantes em determinado período. Segundo Costa (1997), a memória institucional seria aquilo que está 
fixado como parte da história da instituição, os legados, acontecimentos e conquistas.

Sob este prisma, buscamos, neste trabalho, por um lado, reafirmar o papel dos relatórios institucionais como fonte de pesquisa da história institucional e, por outro, mostrar como a Biblioteca Nacional (BN) buscou internacionalizar-se no período de 1905 a 1915. Esse processo de internacionalização será analisado, tendo como recorte temas envolvendo essa internacionalização, explicitados nos relatórios institucionais.

No período selecionado, a Biblioteca passa por grandes transformações, uma vez que, com a perspectiva de ganho de um novo prédio e sua concretização, em 1910, os dirigentes da instituição viram-se obrigados a planejar e desenvolver ações que modernizassem a estrutura física, de pessoal e de ação da Biblioteca.

Falar em modernização da BN implica, necessariamente, reportarnos a Manuel Cícero Peregrino da Silva, diretor da Biblioteca entre 1900 e 1924, o responsável por levar a cabo a tarefa de planejar as profundas mudanças que viriam a ocorrer na instituição. Jurista formado pela Escola de Recife, Peregrino da Silva nasceu no ano de 1866; ao longo de sua vida ocupou vários postos de destaque na vida cultural e política brasileira, tais como presidente do Instituto Histórico e Geográfico Brasileiro, Prefeito do Distrito Federal (então Rio de Janeiro) e Reitor da Universidade do Brasil. Porém, seu trabalho de maior destaque foi à frente da Biblioteca Nacional. Pioneiro na aplicação das técnicas de Documentação no Brasil, Peregrino da Silva fez mudanças profundas no regulamento da instituição, além de conseguir a aprovação da Lei de Depósito Legal, em 1907, e manteve contatos constantes com instituições internacionais (BRASIL. Biblioteca Nacional, c2010).

Em termos metodológicos, a pesquisa consistiu no levantamento dos relatórios constantes das páginas finais dos Anais da Biblioteca entre os anos de 1905 e 1915, disponíveis no site da instituição, buscando-se evidências de iniciativas de internacionalização. Em seguida, foram arroladas todas as seções dos relatórios e, dessas, selecionadas quatro, cujos temas diziam respeito às ações da Biblioteca Nacional em conjunto com instituições estrangeiras. Esses quatro temas foram, então, objeto de análise do presente trabalho.

Tratando-se de textos escritos no início do século $X X$, todas as citações deles extraídas terão suas grafias originais preservadas, com vistas a manter a fidedignidade do texto. Finalmente, as reflexões apresentadas neste trabalho são parte de um projeto de pesquisa de mestrado em andamento no Programa de Pós-Graduação em Ciência da Informação da Universidade de Brasília. 


\section{Contexto da época}

O início do século XX marca um período ainda de afirmação para a República brasileira, proclamada no final do século XIX, e o seu ideal de modernização. Assim, a primeira década do século é marcada por grandes transformações urbanas no coração político do país, o Rio de Janeiro (então Distrito Federal), com a abertura de grandes avenidas e a demolição de grande parte de seu centro antigo, considerado insalubre por sanitaristas, como Oswaldo Cruz (KOK, 2005). A ideia era de urbanizar a cidade, dando-lhe o aspecto moderno que uma nova nação desejava e, ao mesmo tempo, oferecer condições sanitárias apropriadas que evitassem a propagação de doenças.

No bojo de tais ações, conforme nos fala Peregrino da Silva, a Biblioteca aproveita-se de tal ocasião para, enfim, conseguir um novo espaço para sua sede, afinal, "o momento era propicio. Remodelava-se a cidade" (SILVA, 1911, p. 394).

Mas, ainda assim, apesar de possuir um "monumental palacio" (SILVA, 1911), a Biblioteca deveria honrá-lo e buscar preencher as suas estantes. Nesse sentido, foi aprovada a lei de depósito legal; além da aquisição de várias coleções ou recebimento de inúmeras doações.

Contudo, talvez no bojo de fortalecimento da nação brasileira e sua entrada no palco das nações "civilizadas", a Biblioteca busca recuperar parte da história do país presente nos arquivos, museus e bibliotecas do exterior, principalmente da Europa. Dentre as iniciativas do período, a instituição envia missões especiais com o objetivo de descrever e copiar a documentação considerada de relevância para a história do país, conforme apontado nos relatórios consultados. Podemos, talvez, afirmar que essa iniciativa seria o embrião do projeto Resgate que a mesma BN iria desenvolver muitos anos depois, em 1995, com o objetivo de "disponibilizar documentos históricos relativos à História do Brasil existentes em arquivos de outros países, sobretudo Portugal e demais países europeus com os quais tivemos uma história colonial imbricada" (UNIVERSIDADE DE BRASÍLIA, [2013]).

Outro aspecto importante nesse sentido, é que o ideal de modernização da Biblioteca Nacional também levou seu dirigente a visitar ou enviar representantes a várias bibliotecas de outros países. O objetivo era de aprender técnicas de tratamento de acervo, métodos de acondicionamento, planejamento de espaços de consulta, etc. Todas essas ações em consonância com a missão de tornar a Biblioteca Nacional brasileira uma das mais modernas do mundo.

Paralelamente, a Biblioteca Nacional também cria o seu Serviço de Bibliographia e Documentação, em contato direto com o Instituto 
Internacional de Bibliografia de Bruxelas (BRASIL, 1911), iniciativa que parece evidenciar o quanto a instituição desejava acompanhar as mais modernas técnicas biblioteconômicas e/ou documentárias do seu tempo.

Outra ação de destaque foi a adesão da Biblioteca Nacional, em 1909, à Convenção da União de Berna, que objetiva proteção dos direitos intelectuais sobre obras literárias e artísticas. Dessa forma, a Biblioteca compromete-se a preservar os direitos autorais sobre as obras literárias e artísticas dos países membros. E mais:

Art. 135. Além dos documentos officiaes e das obras publicadas por ordem do Governo, conforme foi estatuido na Convenção de Bruxellas de 15 de março de 1886, a Biblioteca enviará a cada um dos paizes, que tomaram parte na Convenção ou a ella adheriram ou ainda a outros paizes, que fôr conveniente accrescentar, publicações que possam tornar conhecido o Brazil e das quaes adquira exemplares em numere sufficiente, distribuindo-os pelas principaes instituições desses paizes, de conformidade com a natureza de cada uma (BRASIL, 1911).

Nesse sentido, parece evidente que para os dirigentes da $\mathrm{BN}, 0$ papel da Biblioteca é também o de promover o Brasil internacionalmente, oferecendo às outras nações obras que pudessem despertar o seu interesse pelo país.

\section{Iniciativas de internacionalização}

Apesar de ser pioneira na sua abrangência e continuidade, a iniciativa de Peregrino da Silva de visitar outras instituições, objetivando o aprendizado de métodos modernos de tratamento do acervo não é nova. Benjamin Franklin Ramiz Galvão, diretor da Biblioteca Nacional entre os anos de 1870 e 1882, foi pioneiro nesse aspecto. Segundo Fonseca (1957, p. 95), no relatório de Ramiz Galvão, este último tece "críticas muito justas e observações de interesse permanente" sobre as bibliotecas europeias.

Assim, o ideal da Biblioteca Nacional parece ancorar-se na busca constante de atualização e modernização dos métodos de tratamento técnico de seu acervo, a exemplo de outras instituições similares do exterior.

\subsection{Pesquisas em arquivos, bibliotecas e museus}

Como dito na introdução, inicialmente identificamos, nos relatórios institucionais do período analisado, todos os temas pelos títulos de suas seções, conforme a tabela 1. 
Tabela 1 - Os anais da Biblioteca Nacional, suas respectivas seções e temas entre os anos de 1905 e 1915

\begin{tabular}{|c|c|}
\hline SEÇÃO DOS ANAIS & PERÍODO \\
\hline 1. a Secção (Secção de Impressos) & $1905-1915$ \\
\hline 2. a Secção (Secção de Manuscritos) & $1905-1915$ \\
\hline 3. a Secção (Secção de Estampas e Numismática) & $1905-1910$ \\
\hline 3. a Secção (Secção de Estampas) & $1911-1915$ \\
\hline 4. ㄹ Secção (Secção de Numismática) & $1911-1915$ \\
\hline Collecção Sousa Lobo & 1912 \\
\hline Comissões nos estados e no estrangeiro & 1913 \\
\hline Conferencias & $1912-1915$ \\
\hline Congressos e associações & $1910-1911$ \\
\hline Congressos internacionaes & 1914 \\
\hline Conselho consultivo & 1914-1915 \\
\hline Contribuição legal & 1908 \\
\hline Convenção da União de Berna & 1909 \\
\hline Curso de Bibliotheconomia & $1912-1915$ \\
\hline Deposito, distribuição e vendas de publicações & $1911-1915$ \\
\hline $\begin{array}{l}\text { Dicionario chorographico, historico e estatistico de } \\
\text { Pernambuco }\end{array}$ & 1909 \\
\hline Direitos auctoraes & $1906-1915$ \\
\hline Edificio e mobiliario & 1911 \\
\hline Edificio & 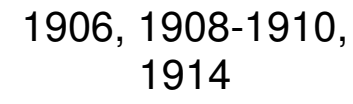 \\
\hline Galeria de retratos & 1912 \\
\hline Galeria dos bemfeitores & 1911,1913 \\
\hline Herma de Teixeira de Mello & 1912 \\
\hline Historias das Indias Occidentaes & 1908 \\
\hline Informações & 1911 \\
\hline Iluminação. Corrente electrica & 1911 \\
\hline Inauguração & 1910 \\
\hline Informações diversas & 1905,1907 \\
\hline Inventario de documentos do Archivo de Ultramar & 1908 \\
\hline Investigações em bibliothecas e archivos & $1911-1912$ \\
\hline Medalha commemorativa & 1911 \\
\hline Mobiliario & 1910,1912 \\
\hline Mudança da biblioteca & 1909 \\
\hline Officinas & $1905-1915$ \\
\hline Pessoal & $1905-1915$ \\
\hline Publicações & 1906 \\
\hline Reclamação do Archivo Publico & 1911 \\
\hline Regulamento da Bibliotheca & 1915 \\
\hline Reorganisação & $1909-1910$ \\
\hline Secretaria & 1905 \\
\hline
\end{tabular}


Serviço de Bibliographia e Documentação

1911-1912

1906-1908, 1910-

1915

1911-1915

1909

1911-1912, 1914-

1915

1909

1912

XVIII Congresso dos Americanistas

Fonte: Elaboração dos autores com base nos Anais consultados.

Posteriormente, de acordo com nossos objetivos, buscamos, por meio da filtragem de seus títulos, os temas objeto da pesquisa, selecionando os relatórios dos anos de 1908 (Inventario de Documentos do Archivo de Ultramar), 1911 (Investigações em Bibliothecas e Archivos), 1912 (Investigações em Bibliothecas e Archivos) e 1913 (Comissões nos Estados e no estrangeiro). Os referidos relatórios trazem pistas sobre as ações da Biblioteca no sentido de enriquecer seu acervo com a cópia de documentos relativos ao Brasil nos arquivos, museus e bibliotecas do exterior, além de, segundo seus dirigentes, servir à Nação, oferecendo provas e testemunhos que ajudem o país em seus interesses, como nos mostra o relatório de 1911, no qual Silva (1912, p. 679) declara,

Tendo-se proposto o conhecido philologo e americanista, Dr. Rodolpho R. Schuller, proceder durante seis mezes, por conta desta Bibliotheca, a investigações em bibliothecas e archivos da Europa, principalmente em Madrid e Sevilha, tendentes á elucidação do problema cartographico e ethnologico da bacia do Amazonas, assim como reunir elementos para o estudo das linguas indigenas sul-americanas, taes como catecismos, grammaticas e vocabularios ineditos, extrahindo copia daquelles que maior interesse offerecessem, e colher materiaes para a bibliographia ethnologica brasileira [...].

Podemos perceber, neste relato, vários dos aspectos mencionados anteriormente, pois a ida do pesquisador aos arquivos e bibliotecas europeias tem por objetivo: a) ajudar a elucidar um problema na fronteira; b) recuperar um pouco da história do Brasil, por meio da busca de registros sobre os índios e seu processo de catequização e civilização; e c) enriquecer o acervo da Biblioteca, por meio da cópia de documentos importantes sobre o Brasil, presentes nestas instituições.

No relatório seguinte, Silva (1913) confirma que Schuller remeteu, ao longo de 1912, cópias de documentos de grande interesse para o país e para a instituição, além de informar que também enviou o "subbibliotecário", João Gomes do Rego, para realizar estudos sobre numismática no Museu Britânico, na Biblioteca Nacional de Paris e na de 
Lisboa, além da Biblioteca Real de Bruxelas, bem como nos gabinetes que achasse conveniente visitar, tendo por finalidade compreender sistemas de classificação adotados, métodos de tratamento etc. (SILVA, 1913).

No relatório subsequente, Silva (1914) fala sobre o retorno do "subbibliotecário", destacando que este fizera o que lhe fora designado e que os resultados foram apresentados em relatório específico.

Por fim, o relatório de 1908 (SILVA, 1909) informa que o diretor do Archivo de Marinha e Ultramar da Biblioteca Nacional de Lisboa, Eduardo de Castro e Almeida, sugeriu à Biblioteca que organizasse, por conta do governo brasileiro, inventário de documentos relativos ao Brasil existente naquela seção, extraindo deles representações ou copiando-os na íntegra. Segundo o relato, a proposta foi submetida ao Ministério da Justiça e Negócios Interiores e fora aprovada, além de declarar que foram extraídos 6.425 verbetes referentes a 6.022 documentos, sem trazer informações sobre cópias

\subsection{Intercâmbio de acervos}

Outro aspecto do relacionamento da Biblioteca com instituições estrangeiras se deu no âmbito do intercâmbio de acervo, pois a instituição se tornou o órgão brasileiro responsável pelas permutações internacionais. Assim:

Art. 136. Como estação intermediaria, a Bibliotheca estenderá a quaesquer paizes a sua interferencia, incumbindo-se gratuitamente de:

10, encaminhar aos diversos estabelecimentos estrangeiros, encarregados desse serviço, as remessas provenientes de instituições scientificas, litterarias, etc., e destinadas a instituições semelhantes;

20, enviar directamente ás instituições dos paizes, onde não houver estação intermediaria, as publicações que lhes forem destinadas;

30, receber do estrangeiro e fazer entregar no Brazil as que procederem daquelles estabelecimentos ou instituições, dando prévio aviso aos destinatarios e enviando-as pelo correio, quando esse meio de transporte fôr autorizado (BRASIL, 1911).

Desta forma, a Biblioteca Nacional se estabelecia como líder regional na articulação com organismos internacionais e no âmbito das trocas culturais com outros países. 
$\mathrm{Na}$ consulta aos relatórios, podemos perceber que a maioria das obras enviadas pela Biblioteca ao exterior eram publicações da própria Biblioteca, tais como os Anais e relatórios governamentais. A exceção ocorria quando o pedido era específico e a instituição solicitava uma determinada obra, como foi o caso do Instituto Internacional de Bibliografia, que, em 1910, solicitou a obra de Menezes Brum "Estampas gravadas por Guilherme Fr. Lour Debie" (INSTITUTO INTERNACIONAL DE BIBLIOGRAFIA, 1910, p. 1).

A seção que descreve, em 1906, as ações do Serviço de Permutações da Biblioteca (SILVA, 1906), informa que as instituições que cederam obras para o Serviço foram: o Instituto Histórico e Geográfico Brasileiro, os Ministérios da Justiça e Negócios Interiores, Relações Exteriores e Fazenda, a Repartição da Carta Marítima, a Imprensa Nacional, as Secretarias do Senado Federal e da Câmara dos Deputados e - Museu Goeldi. Informa, também, que o número de instituições correspondentes no exterior passou de 211 para 214. Souza (1915) informa, na mesma seção do relatório de 1915, que o número de correspondentes internacionais passou para 272. Um acréscimo de 58 instituições no período de 10 anos.

$\mathrm{Na}$ lista das instituições com as quais a Biblioteca mantinha contato, foram identificadas: Smithsonian Institution (Washington); Ministère de I'Instruction Publique et des Beaux-Arts (Paris); Department of Foreign Affairs (Tóquio); Biblioteca Nazionale Vittorio Emanuele (Roma); e The University Library (Califórnia).

Tal fato parece evidenciar o aspecto de liderança que a Biblioteca desempenhava no país, com relação ao contato com instituições estrangeiras, sobretudo por servir de mediação entre as instituições estrangeiras e nacionais.

\section{Considerações finais}

Como portadores da memória, os relatórios institucionais, como os da Biblioteca Nacional, ofereceram importantes pistas sobre o passado da instituição. Por meio dos vestígios encontrados nesse corpus, é possível recontar parte da história da instituição.

Embora, nos limites deste artigo, não possamos explorar o que parece ter sido uma colaboração estreita entre a Biblioteca Nacional e o Ministério das Relações Exteriores do Brasil para manter o contato com instituições estrangeiras, bem como auxiliar o seu corpo técnico no desempenho de suas funções no exterior, esse é um dos aspectos a ser abordado na pesquisa de mestrado em andamento. Essa parceria parece institucionalizar, ainda mais, o desejo de internacionalização da Biblioteca Nacional, bem como parece evidenciar o apoio governamental a essa iniciativa. 
Sob este prisma, também podemos notar que a autorização, por parte do governo federal, para a fundação do curso de Biblioteconomia na instituição, foi mais um passo no sentido de modernizar a Biblioteca e que nela fossem adotados os métodos apreendidos nas grandes instituições estrangeiras. Assim, a BN também poderia formar pessoal especializado para o tratamento de seu acervo.

É importante ressaltar que a abordagem que estamos desenvolvendo em nossa pesquisa revela-se inédita, particularmente quanto à exploração desses documentos. Até o momento, não conseguimos recuperar referências que tratassem da internacionalização da Biblioteca Nacional, no sentido aqui analisado. Desta forma, podemos concluir que esse ainda é um campo a ser explorado e que pode trazer importantes contribuições para o estudo historiográfico das instituições brasileiras.

\section{Referências}

BRASIL. Biblioteca Nacional. Manuel Cícero Peregrino da Silva. [Rio de Janeiro]: Biblioteca Nacional, c2010. Disponível em: <http://bndigital.bn.br/200anos/manuelCicero.html>. Acesso em: 12 fev. 2013.

BRASIL. Decreto no 8.835, de 11 de julho de 1911. Approva o regulamento da Bibliotheca Nacional. Diário Oficial da União, 16 jul. 1911. Disponível em: <http://www2.camara.leg.br/legin/fed/decret/19101919/decreto-8835-11-julho-1911-502890-republicacao-102224pe.html>. Acesso em: 9 fev. 2013.

COSTA, I. T. M. Memória institucional: a construção conceitual numa abordagem teórico-metodológica. 1997. Tese (Doutorado em Ciência da Informação) - IBICT-UFRJ, Rio de Janeiro.

DURANTI, L. Registros documentais contemporâneos como provas de ação. Estudos históricos, Rio de Janeiro, v. 7, n. 13, p. 49-64, 1994.

FONSECA, E. N. da. Desenvolvimento da Biblioteconomia e da Bibliografia no Brasil. Revista do Livro, ano 2, n. 5, p. 95-124, mar. 1957.

INSTITUTO INTERNACIONAL DE BIBLIOGRAFIA. Cartão posta a Biblioteca Nacional solicitando obra de Menezes Brum. Bruxelas, [12 de janeiro] de 1910. Original, Datilografado, Manuscrito, 1 cartão. (Coleção Biblioteca Nacional, códice 68,2,005).

KOK, G. Rio de Janeiro na época da Av. Central. São Paulo: Bei Comunicação, 2005. 
SILVA, M. C. P. da. A Bibliotheca em 1908: relatorio. Annaes da Bibliotheca Nacional do Rio de Janeiro, v. 31, p. 654-678, 1909. Disponível em: <http://objdigital.bn.br/acervo_digital/anais/anais_031_1909.pdf>. Acesso em: 10 fev. 2013.

SILVA, M. C. P. da. A Bibliotheca Nacional em 1910: relatorio. Annaes da Bibliotheca Nacional do Rio de Janeiro, v. 33, p. 367-397, 1911. Disponível em: <http://objdigital.bn.br/acervo_digital/anais/anais_033_1911.pdf>. Acesso em: 10 fev. 2013.

SILVA, M. C. P. da. A Bibliotheca Nacional em 1911: relatorio. Annaes da Bibliotheca Nacional do Rio de Janeiro, v. 34, p. 648-684, 1912. Disponível em: <http://objdigital.bn.br/acervo_digital/anais/anais_034_1912.pdf>. Acesso em: 10 fev. 2013.

SILVA, M. C. P. da. A Bibliotheca Nacional em 1912: relatorio. Annaes da Bibliotheca Nacional do Rio de Janeiro, v. 35, p. 419-442, 1913. Disponível em: <http://objdigital.bn.br/acervo_digital/anais/anais_035_1913.pdf>. Acesso em: 10 fev. 2013.

SILVA, M. C. P. da. A Bibliotheca Nacional em 1913: relatorio. Annaes da Bibliotheca Nacional do Rio de Janeiro, v. 36, p. 664-689, 1914. Disponível em: <http://objdigital.bn.br/acervo_digital/anais/anais_036_1914.pdf>. Acesso em: 10 fev. 2013.

SOUZA, A. L. de. A Bibliotheca em 1915: relatorio. Annaes da Bibliotheca Nacional do Rio de Janeiro, v. 38, p. 348-372, 1916. Disponível em: <http://objdigital.bn.br/acervo_digital/anais/anais_038_1916.pdf>. Acesso em: 10 fev. 2013.

UNIVERSIDADE DE BRASÍLIA. Centro de Memória Digital. Histórico do Projeto Resgate. Brasília: UnB, [2013]. Disponível em: <http://www.cmd.unb.br/resgate_index.php>. Acesso em: 15 fev. 2013. 